Check for updates

Cite this: Environ. Sci.: Processes Impacts, 2021, 23, 1663

Received 1st May 2021

Accepted 11th October 2021

DOI: 10.1039/d1em00175b

rsc.li/espi

\section{Battling the known unknowns: a synoptic review of aquatic plastics research from Australia, the United Kingdom and China $\uparrow$}

\author{
Harriet L. Paterson, ${ }^{a}$ Jessica L. Stead, ${ }^{\mathrm{b}}$ Thomas Crutchett, (D) ${ }^{\mathrm{c}}$ Renae K. Hovey, ${ }^{c}$ \\ Benjamin M. Ford, ${ }^{a}$ Peter Speldewinde, ${ }^{a}$ Lina M. Zapata-Restrepo, ${ }^{d}$ Lu Yanfang, ${ }^{e}$ \\ Xiaoyu Zhang ${ }^{\mathrm{e}}$ and Andrew B. Cundy (D)*bf
}

Plastic pollution is a global environmental and human health issue, with plastics now ubiquitous in the environment and biota. Despite extensive international research, key knowledge gaps ("known unknowns") remain around ecosystem-scale and human health impacts of plastics in the environment, particularly in limnetic, coastal and marine systems. Here we review aquatic plastics research in three contrasting geographic and cultural settings, selected to present a gradient of heavily urbanised (and high population density) to less urbanised (and low population density) areas: China, the United Kingdom (UK), and Australia. Research from each country has varying environmental focus (for example, biotafocussed studies in Australia target various bird, fish, turtle and seal species, while UK and China-based studies focus on commercially important organisms such as bivalves, fish and decapods), and uses varying methods and reporting units (e.g. mean, median or range). This has resulted in aquatic plastics datasets that are hard to compare directly, supporting the need to converge on standardised sampling methods, and bioindicator species. While all the study nations show plastics contamination, often at high levels, datasets are variable and do not clearly demonstrate pollution gradients.

Environmental significance

Plastics pollution is a global environmental and human health issue, with plastics now ubiquitous in the environment. Despite extensive international research, key knowledge gaps ("known unknowns") remain around ecosystem-scale and human health impacts of plastics in the aquatic environment. Here we review aquatic plastics research in three contrasting geographic and cultural settings, which present a gradient of heavily urbanised to less urbanised, low population density, environments: China, the United Kingdom, and Australia. While all study nations show plastics contamination, often at high levels, in various environmental matrices, datasets are variable and do not clearly demonstrate pollution gradients. We identify key research and management challenges for each nation, and a need to converge on standardised methods and bioindicator species to make global comparisons more reliable.

${ }^{a}$ School of Agriculture and the Environment, University of Western Australia, Crawley, Western Australia 6009, Australia.E-mail: Harriet.Paterson@uwa.edu.au; ben.ford@ uwa.edu.au; peter.speldewinde@uwa.edu.au

${ }^{b}$ School of Ocean and Earth Science, National Oceanography Centre (Southampton), University of Southampton, European Way, Southampton, SO14 3ZH, UK. E-mail: J. L.Stead@soton.ac.uk; A.Cundy@soton.ac.uk

${ }^{c}$ Oceans Institute and School of Biological Sciences, University of Western Australia, Crawley, Western Australia 6009, Australia. E-mail: t.crutchett@gmail.com; renae. hovey@uwa.edu.au

${ }^{d}$ Faculty of Environmental and Life Sciences, University of Southampton, University Road, Southampton SO17 1BJ, UK. E-mail: lmzr1f20@soton.ac.uk

${ }^{e}$ Key Laboratory of Geoscience Big Data and Deep Resource of Zhejiang Province, School of Earth Sciences, Zhejiang University, Hangzhou 310027, China. E-mail: 21938009@zju.edu.cn; zhang_xiaoyu@zju.edu.cn

${ }^{f}$ Hong Kong Branch of Southern Marine Science and Engineering Guangdong Laboratory, Guangzhou, Hong Kong, China

$\dagger$ Electronic supplementary information (ESI) available. See DOI: 10.1039/d1em00175b

\section{Introduction}

Plastic pollution is a globally recognised environmental, ecosystem, and human health issue,$^{1-3}$ with plastics now ubiquitous in the environment and biological systems. ${ }^{4-6}$ Despite large-scale international concern and research attention (summarised in Wang ${ }^{7}$ ), recognised knowledge gaps (which we term here "known unknowns") remain around ecosystem-scale and human health impacts of plastics, and the fluxes and masses of plastic present in global systems. Accurate information on the latter is fundamentally important if the environmental risk is to be assessed and minimised. This is particularly true for limnetic, coastal and marine systems. Based on current data, estimates of the mass of plastic, present in sinks or reservoirs (e.g. seabed, biota, water column) and physically removed (e.g. beach cleaning), are significantly less than masses estimated from input data - with $90 \%$ of plastic debris "missing". 8,9 This 
problem is particularly severe for microplastics (MP), which are plastic particles up to $5 \mathrm{~mm}$ in size. ${ }^{10}$ The lower end of this size range $(<300 \mu \mathrm{m})$ has been under-studied or not reliably quantified to date, even though these smaller particles are likely to be more reactive and readily ingested by fauna at the base of the food web. ${ }^{11}$ Estimates of the amount of MP on the sea surface vary enormously between 6350 and 236000 metric tons, with the greatest amounts in the ocean gyres. ${ }^{\mathbf{8} 12,13}$ The abundance and distribution of MP in deeper ocean waters remains virtually unknown, even though recent work suggests that the ocean interior conceals high loads of small-sized plastic debris which can balance and even exceed the estimated plastic inputs into the ocean since $1950 .{ }^{14}$ Indeed, while global estimates have been produced for overall masses of river plastic entering the ocean, ${ }^{15}$ systematic and accurate budgets for MP are lacking. Although much research is currently underway, we still know relatively little about land-ocean MP fluxes in different systems, the relative importance of and dynamics between sources and sinks, and the critical processes that control MP fate in aquatic ecosystems. The current uncertainties in budgets and fluxes are at least partly due to a lack of standardised data collection and measurement methods, meaning that local observations are often hard to generalise into a consistent global or even regional picture. ${ }^{9,16,17}$

The recently established TransPlas project attempts to address some of these knowledge gaps, particularly around MP, by bringing together universities in three contrasting regions (Zhejiang University, China; University of Southampton, United Kingdom (UK); and University of Western Australia, Australia), and co-ordinating research and data collection using standardised methods at test sites along the east China, southern UK and southwest Australian coastlines, which represent a gradient of heavily urbanised to less urbanised, low population density, environments.

As a first step, we synoptically review existing aquatic plastics research in the three contrasting study regions of TransPlas and assess the variation in research efforts across a range of thematic scientific focus areas. In conducting this examination, we:

(1) Review the contamination levels observed and the metrics used.

(2) Identify areas of expertise, and commonalities (or divergence) in research focus.

(3) Highlight the known unknowns; and.

(4) Assess current management strategies, which can be used to better understand the issues in each system and prioritise future research efforts.

\section{Methods}

We conducted a systematic literature search in Google Scholar and the "Searching Engine System of Literature in Chinese" (CNKI, to capture Chinese language papers), using the keywords “Marine Debris”, "Marine Plastic”, and “Microplastic (微塑料)” and either "Australia", "China" or "UK". This was to restrict the scope to papers focused on our study regions, although this search also yielded freshwater papers which have been included. Papers were excluded if researchers were not resident in the host countries or only had limited data from target countries, to avoid including information primarily derived from another country.

For each reference, the year of publication, country, the study subject (biological or physical), fundamental values (abundance, size, concentration, colour etc.) and units of measurement and keywords were captured where available. Values and units were not retained for review articles. Papers were not included if records of plastic were incidental to another task or included multiple countries, and only publications published or available on-line by the end of 2019 (the date of the literature survey) were included. Each publication was categorised into one of four major groups, by thematic focus (termed here level 1, Table 1). Papers within each of these groups were then further categorised into subgroups based on their sampling, analytical or discussion focus, labelled level 2 (Table 1).

The package 'ggplot'18 in RStudio, ${ }^{19}$ was used to explore the types of research and subject areas targeted by each country.

\section{Publication trends with time and by level 1 (thematic) category}

A total of 439 publications were recovered, 139 from Australia, 116 from the UK and 184 from China in English (Fig. 1). The earliest record was from the UK in 1974, with Australia following in 1988. The abundance of publications from each of these countries follows the temporal publication trend identified by other authors, ${ }^{20-22}$ with sporadic publications between the 1970 s and the 2000s, followed by consistent publication from 2009 in the UK and 2005 in Australia. In our literature search, the first English language paper from China was published in 2011, ${ }^{23}$ although the earliest Chinese work reported elsewhere was from 2008. ${ }^{21}$ In 2018 and 2019, China published more information than Australia and the UK combined.

Of the four category groupings used here, $48 \%$ of publications were classified as "sources distribution and trend", with "environmental interaction impact" at $39 \%$, and the least studied are "culture and sustainable futures" at nine percent and "societal impacts" at four percent (Fig. 1).

\section{Publications by focus area (level 2 categorisation): coverage and metrics used, and contamination levels observed}

\subsection{Biota}

Australia contributed the most papers to the subcategory of "Biota", examining how bird, fish, turtle and seal species interact with plastic (Fig. 2). Publications from China and the UK have mainly concentrated on commercially important organisms such as bivalves, ${ }^{24}$ fish $^{25}$ and decapods such as Nephrophs norvegicus (UK) ${ }^{26}$ (Fig. 3 and 4). The metrics used to 
Table 1 Categorisation levels and definitions used to classify publications for the study of aquatic plastics publications between Australia, China and the United Kingdom. Level 1 divides the works into one of four general thematic topics, and level 2 subsequently groups like subjects within level 1 based on their sampling, analytical or discussion focus. Manuscripts were included in one category per level only, based on the dominant focus of the study. The full publication database, with level 1 and level 2 categorisation, is presented in ESI (ESI, Table S1)

Categories level 1

Sources, distribution and trend (SDT)

Environmental interaction impact (EII)

Culture, sustainable future (CSF)

Societal impacts (SI)

Categories level 2

Biota

Substrate

Plastic-associated contaminants

Effects

Governance

Physical processes

Review

Techniques
Estimates the abundance and patterns of plastic in all habitats in space and time

Interaction between animals and plastics including ingestion and food web dynamics, changes in animal behaviour, chemical impacts on animals and accumulation and sorbing of chemicals in the environment Usually government-led (policy) frameworks for human behaviour and modification of the environment to reduce plastic pollution

The economic impacts of plastic debris on the home and businesses and societal responses to single-use plastic

\section{(1)}

describe the impact of plastic on each group of organisms differ according to their ecology and size.

Australia has conducted the most research on birds with 23 documents; followed by the UK and China contributing six and one respectively (Fig. 2-4). Research has largely focused on Procellariiform (petrels) and Suliforme (gannets) species. The most frequently used metric was "percentage of contaminated individuals" or "frequency of occurrence" (65\%), followed by the mean number of items ingested $(50 \%)$ then the range (35\%), and periodically, the median (11\%). For example, a recent Australian study examined ingested debris in 51 marine bird species, reporting that the greatest number of items per individual bird was 40 (Puffinus griseus). Of the 1734 birds that contained plastic the mean and median number of items ingested was 4.95 and three, respectively. ${ }^{27}$ The general size of plastic ingested by birds has been described by Roman et al. $(2019)^{28}$ who introduced the phrase "danger zone" to describe the most frequently ingested size of plastic particles ingested by birds $(2-10 \mathrm{~mm}){ }^{27}$
All papers concerned with organisms, ranging from larger organisms (e.g. Mammals, birds and fish) to microorganisms. EII includes ingestion rates and types and SDT includes distribution of areas Different habitats, including beaches, sediment, water, ocean, river and estuaries. SDT includes where plastic may accumulate, EII where plastics and associated chemicals have an impact on fauna

Toxic chemicals such as plasticisers - additives such as phthalates used to soften manufactured plastics, and other additives such as bisphenol A (BPA), and adsorption of compounds already in the environment to plastic. SDT covers contaminates associated with plastic and EII with plastic interacting with chemical contamination of fauna Where plastics and their products have an effect on an animal or the environment in terms of (EII) chemical exposure or (SDT) entanglement in nets

Captures governance, management and actions undertaken by people. SDT includes community clean-ups, SI civil behaviour change and reporting, EII management behaviour change, CSF government processes

Physical processes that influence the distribution of plastics and changes experienced in the environment, including biochemical processes, mostly EII

Papers that reviewed existing information on a variety of topics Papers that discussed methods and assessment across EII, SDT and CSF
Many Australian papers have explored the presence of plastic in bird nests and the effects on juvenile or fledgling birds..$^{29,30}$ Hardesty et al. (2015) introduced a novel technique to sample the presence of phthalates in preening oil of live birds, in a nondestructive manner. ${ }^{31}$ Research from the UK investigates various topics, including the use of plastic in nesting material, and the ingestion and excretion of plastic debris. ${ }^{32}$ There was one study from China investigating plastic ingestion by birds, reporting that four of the nine birds studied contained plastic, and a total of 56 plastic items were recorded..$^{33}$

Collectively there were 25 papers on fish, with Australia, China and the UK contributing five, eleven and nine, respectively. All papers quantify the average number of plastic items ingested per individual, with China reporting the highest rate at 22.21 in Thryssa kammalensis. ${ }^{34}$ There were also papers from each country that observed fish with no plastic ingestion: Australia 1, China 6 and the UK 6. Other metrics were used periodically, including; the mass of plastic per individual (4), the 

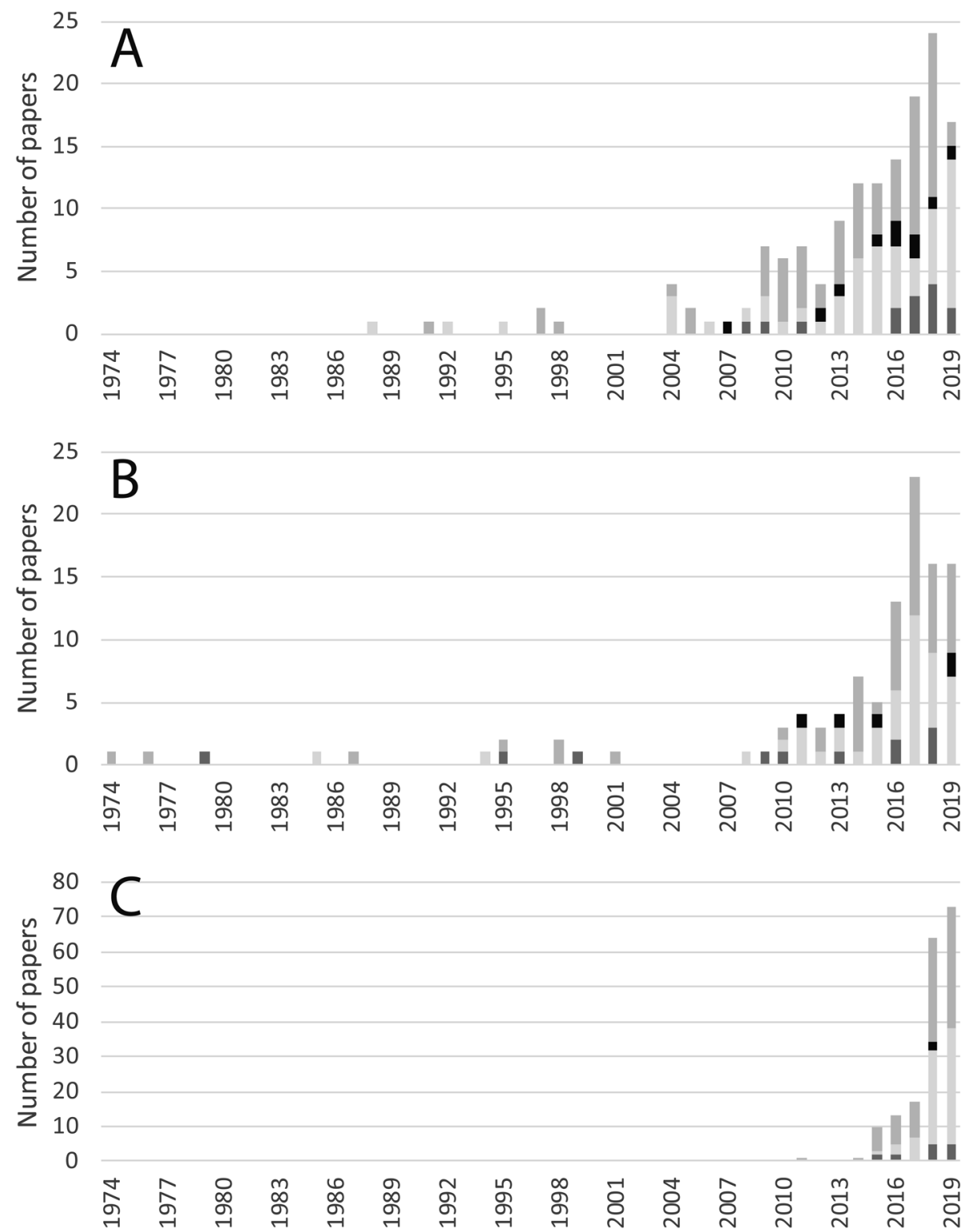

- Culture sustainable future

- Societal impacts
Environmental interaction impact

- Sources distribution and trend

Fig. 1 Annual production of literature covering aquatic plastic debris in Australia (a), the United Kingdom (b) and China (c). Material includes peerreviewed articles and government and NGO literature. Literature has been classed in one of four (level 1) categories (see text for discussion).

number of items retained in the gills (2), and the frequency of occurrence of plastic ingestion (11).

China and the UK have published the most research on commercially important marine species such as Nephrophs norvegicus in the $\mathrm{UK}^{26}$ and bivalves in China. ${ }^{24}$ China has ten investigations on bivalves (mussels and oysters), the UK has nine and Australia one. ${ }^{35}$ Metrics included items/individual and/or items/mass of organisms. The range for items/ individual was 0.4-57.2, and the concentration for bivalve flesh was $0.086-10.5$ items per $g$ of tissue with the higher values reported from China. ${ }^{36,37}$ Scientists from the UK have investigated decapods, targeting the langoustine Nephrops norvegicus (lobster). ${ }^{26,38}$ While decapods have been investigated by Chinese researchers, this is often in association with another subject and is not the main topic. ${ }^{39}$ The only country to examine plastic in Holothuroidea (sea cucumbers) has been China, reflecting its commercial interest in this farmed product. ${ }^{40,41}$

For marine mammals entanglement rather than ingestion has been the focus, with four Australian papers and one paper from the UK. The percentage of the total population tangled was recorded, except for one paper where the number of entanglements was reported. Australian papers report entanglement rates of $<2 \%$ and the study from the UK found a rate between 3.6 and $5 \% .{ }^{42}$ 


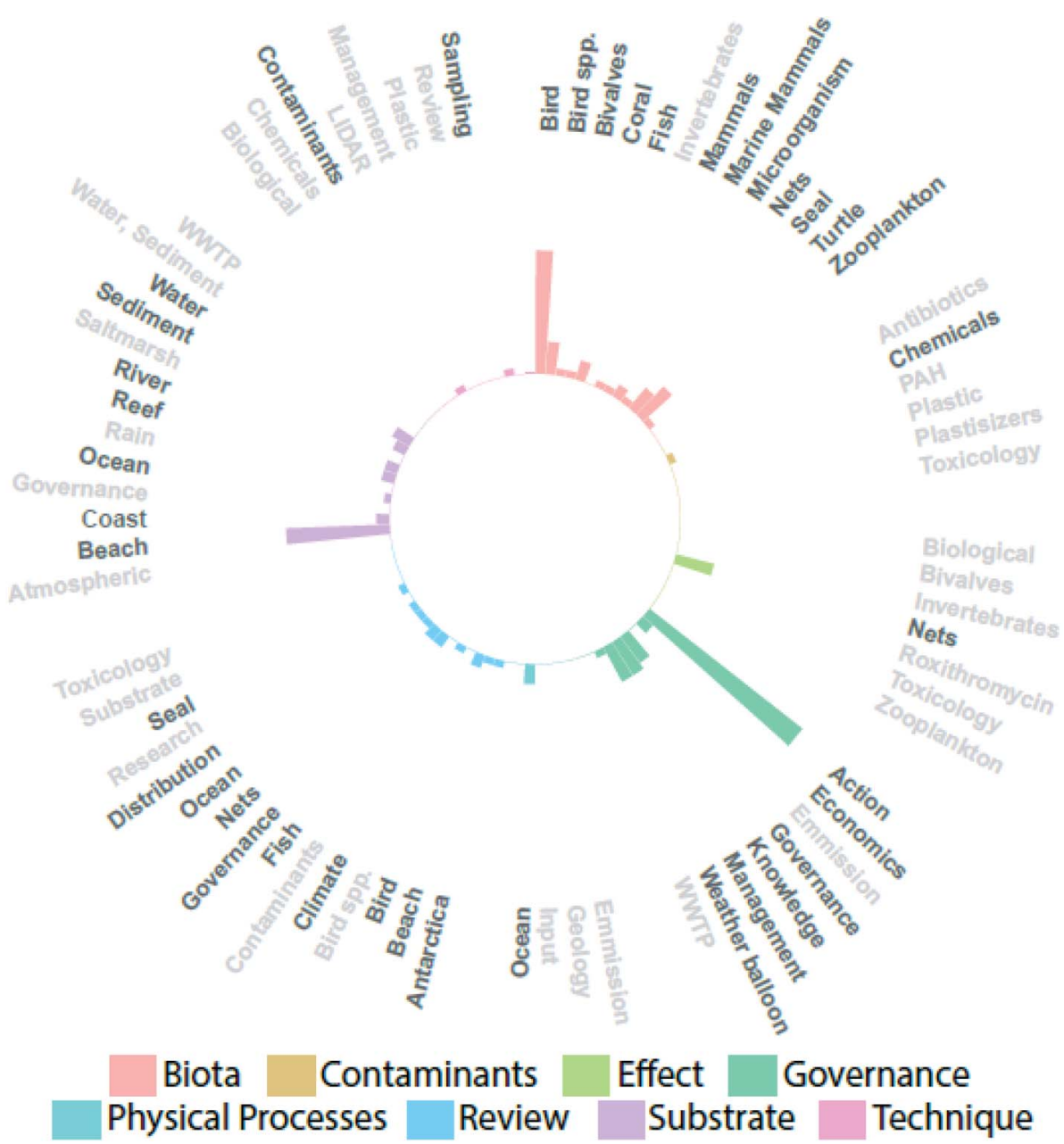

Fig. 2 Circular Bar plot of the subject areas of aquatic plastic debris literature for Australia up to the end of 2019. Papers are organised by level 2 categorisation (lower legend), with specific study focus (or sub-topic, see ESI Table S1†) also highlighted in the detailed radial bar labels. In the main legend, "contaminants" refers to plastic-associated contaminants (see Table 1 for categorisation and definitions used). Total papers 139, $\max$ bar $=22$.

Most of the research on turtles has been undertaken in Australia with one publication from China. Of the seven papers on turtles, four give estimates of the number of items ingested by an individual turtle. One paper models the threats to the animals, ${ }^{43}$ another estimates the number of turtles lost for a given length of lost fishing net ${ }^{44}$ and the remaining paper examines the visual system of turtles and their ability to distinguish plastic. ${ }^{45}$ The highest published number of ingested particles is 329 for an individual sea turtle. ${ }^{46}$ One Australian paper examined 20 stranded sea turtles (1 Caretta caretta, 19 Chelonia mydas) and observed no plastic ingestion. ${ }^{47}$

There is only one record for each of coral, microorganisms and zooplankton. In general, estimates are expressed as a percentage of the population affected and/or items per individual (although for scleractinian corals, an ingestion rate is given $^{48}$ ). The three invertebrate papers from the UK (excluding those mentioned above [mussels and decapods]) have focused on three different aspects, (1) the fate of plastic over extended periods, ${ }^{49}$ (2) microplastics in riverine macroinvertebrates, ${ }^{50}$ and (3) pollution caused by antifouling paint. ${ }^{51}$ China has investigated plastics in zooplankton in five publications, and scientists from the UK have published four laboratory studies into the uptake and effects of plastic on zooplankton. ${ }^{52-55}$ In contrast, Australia has one paper on midge larvae (Chironomus tepperi). ${ }^{111}$ Cetaceans have been covered by two papers from the UK and one from Australia, investigating the gut content of stranded whales ${ }^{56,57}$ and the behaviour of an entangled animal..$^{58}$

Studies on the uptake of plastic debris by biota utilise a range of units (Table 2). The most common metric is abundance per individual (34\%) followed by frequency of occurrence. The studies available do not identify any consistent gradient in plastics contamination when comparing the maximum concentrations recorded in each country (Table 2).

\subsection{Substrate}

The substrates of water and sediment represent about $30 \%$ of all papers in this review, and they were often sampled together. China has conducted the most research (Fig. 4), with 26 and 24 documents examining water and sediment, respectively. 


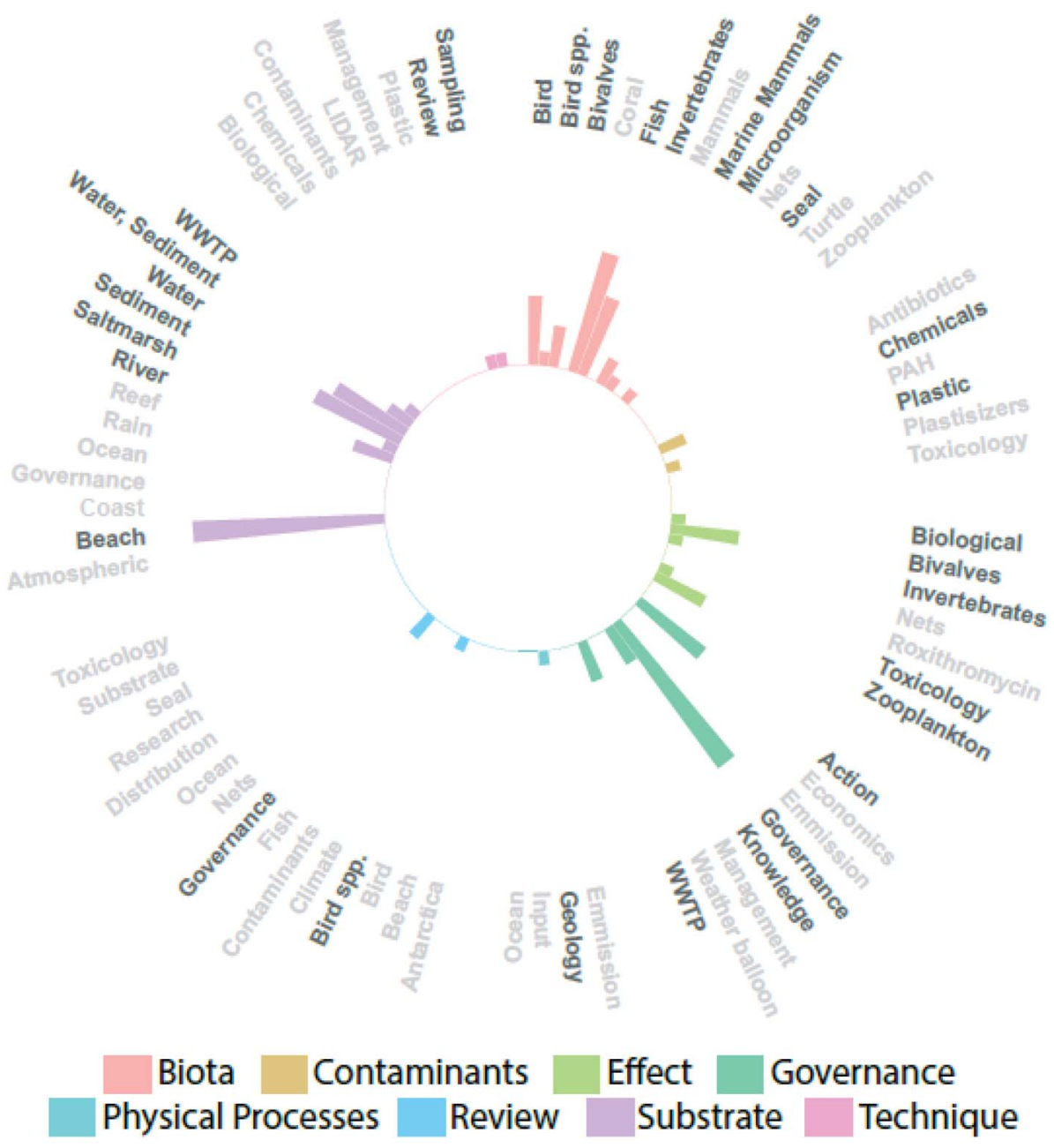

Fig. 3 Circular bar plot of the subject areas of aquatic plastic debris literature for the United Kingdom up to the end of 2019. Papers are organised by level 2 categorisation (lower legend), with specific study focus (or sub-topic, see ESI Table S1†) also highlighted in the detailed radial bar labels. In the main legend, "contaminants" refers to plastic-associated contaminants (see Table 1 for categorisation and definitions used). Total papers 116 , $\max$ bar $=14$.

Analysis of a subset of eight papers examining sediment from China, published in 2019, indicates how divergent methods are. Each paper used different volumes of sediment, from different depths, collected using a variety of tools. Samples were generally dried at $60{ }^{\circ} \mathrm{C}$ and digested in $30 \% \mathrm{H}_{2} \mathrm{O}_{2}$, however the supernatant was filtered through filter papers with different pore sizes and sediment was not always sieved. The lack of commonality among these papers suggests they are not comparable even within China. The most used units are "items $\mathrm{kg}^{-1}$ " for sediment and "items $\mathrm{m}^{-3}$ " for water (Table 3). "Items $\mathrm{m}^{-2}$ " is also used for sediments and when the surface of the water (e.g. the surface microlayer or SML) is considered, "items $\mathrm{km}^{-2}$ " is often used in water column studies where manta net or trawl sampling have been used. "items $\mathrm{L}^{-1}$ " is also used for some studies such as those on the SML by Anderson et al. ${ }^{66}$ but is more often associated with comparisons between ambient plastic concentrations in the water column and a biological model organism such as coral ${ }^{67}$ or bivalves. ${ }^{68}$ Other units such as "items $100 \mathrm{~g}^{-1}$ sediment" are used less frequently, and a few papers used the term "pieces" rather than "items". Some of the highest plastic concentrations were found in China (Table 3), focusing on the Yellow Sea, the Bohai Sea and the East China Sea near Shanghai. There are also papers from the waterways around Hong Kong, the Yangtze River and the Three Gorges Dam. ${ }^{69}$

In terms of substrates, beaches have been examined in all three countries, 16 in Australia, eight in China and 14 in the UK. River sediments are the next most studied substrate, with nine studies in China and three in the UK. Sediments from freshwater lakes have been studied in China $(n=\operatorname{six})$ and the UK $(n=$ one). Benthic sediments have also been studied in all three countries, two studies in Australia, nine in China and two in the UK. Estuarine sediments have also been studied in China and the UK, but no recorded studies were found for Australia.

\subsection{Plastic-associated contaminants}

China has produced 12 papers concerned with contaminants found on or associated with plastics pollution (Fig. 4), and half 


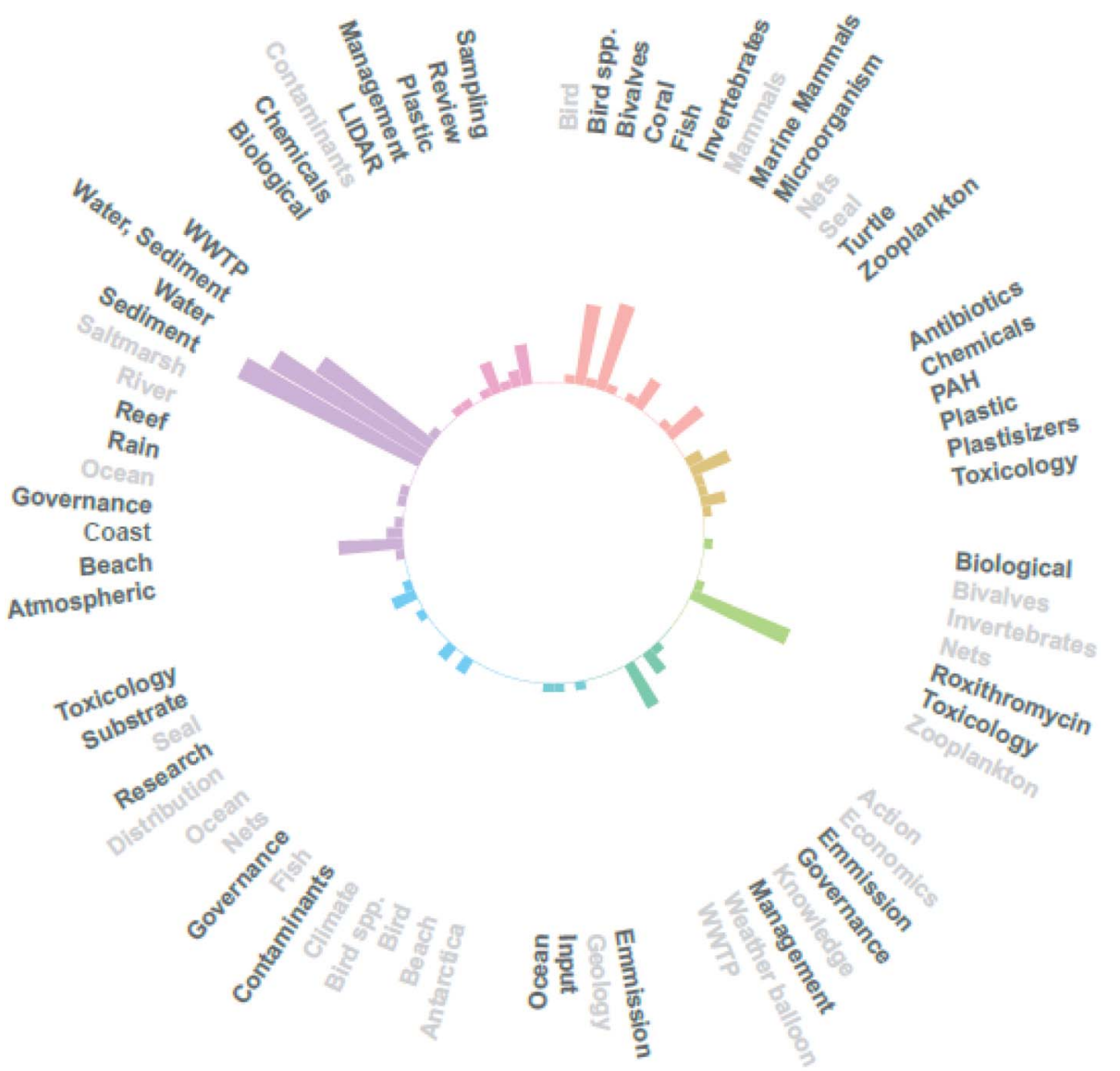

\section{Biota Contaminants Effect Governance \\ Physical Processes Review Substrate Technique}

Fig. 4 Circular bar plot of the subject areas of aquatic plastic debris literature for China up to the end of 2019. Papers are organised by level 2 categorisation (lower legend), with specific study focus (or sub-topic, see ESI Table S1 $\dagger$ ) also highlighted in the detailed radial bar labels. In the main legend, "contaminants" refers to plastic-associated contaminants (see Table 1 for categorisation and definitions used). Total papers 184, $\max \operatorname{bar}=24$.

of these are written in the Chinese language. Six are concerned with chemicals including polycyclic aromatic hydrocarbons, four with plasticisers (including organophosphorus esters and phthalates) and two with antibiotics. Several works have concentrated on the adsorption of chemicals such as polycyclic aromatic hydrocarbons (PAH), organic contaminants, and polychlorinated biphenyls (PCB) to plastic debris and microplastics. ${ }^{81-84}$ These works have identified plastic as a potential mechanism for chemical transportation in aquatic environments ${ }^{82}$ and to concentrate some chemicals in areas of intense plastic use such as mariculture facilities. ${ }^{83}$ Contaminants were generally expressed at $\mathrm{ng}$ of the chemical per $\mathrm{g}$ of polymer, reflecting a degree of standardisation in reporting within the discipline of plastic-associated contaminant research, although extraction and analytical methods (and so chemical recoveries, and contaminants of focus), vary.

Table 2 The highest values for plastic concentration in biota for Australia, the UK and China with respective references shown. The number of texts using this notation for Australia, the UK and China is in []

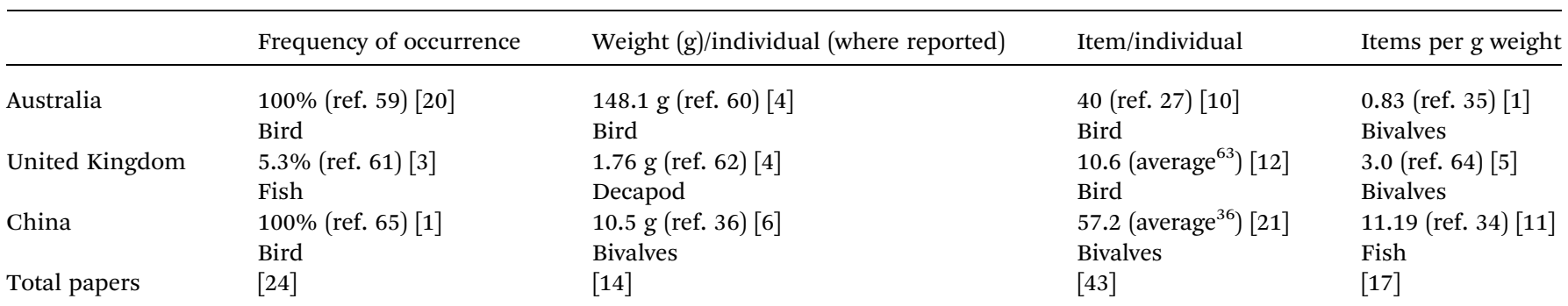


Table 3 The highest values for plastic concentration in sediment and water for Australia, the UK and China with respective references shown. The number of texts using this notation for Australia, the UK and China is in []

\begin{tabular}{|c|c|c|c|c|c|}
\hline & Items kg ${ }^{-1}$ & Items $\mathrm{m}^{-3}$ & Items $\mathrm{m}^{-2}$ & Items $\mathrm{km}^{-2}$ & ${\text { Items } \mathrm{L}^{-1}}^{-1}$ \\
\hline \multicolumn{6}{|l|}{ Australia } \\
\hline \multicolumn{6}{|l|}{ Sediment } \\
\hline Water & & & & $6 \times 10^{4}($ ref. 70$)[2]$ & \\
\hline \multicolumn{6}{|c|}{ United Kingdom } \\
\hline Sediment & $2.5 \times 10^{3}($ ref. 71$)[2]$ & 1.6 (ref. 72) [1] & $5.2 \times 10^{5}$ (ref. 74) [3] & & \\
\hline Water & & 2.4 (ref. 73) [1] & & & 93 (ref. 66) [1] \\
\hline \multicolumn{6}{|l|}{ China } \\
\hline Sediment & $3.3 \times 10^{5}($ ref. 75$)[29]$ & & $4.4 \times 10^{3}($ ref. 77$)[4]$ & & 0.57 (ref. 79) [1] \\
\hline Water & & $342 \times 10^{5}($ ref. 76$)[20]$ & & $136 \times 10^{5}($ ref. 78) $[4]$ & $1.2 \times 10^{3}$ (ref. 80) [4] \\
\hline Total papers & {$[31]$} & {$[22]$} & {$[7]$} & {$[6]$} & {$[6]$} \\
\hline
\end{tabular}

The UK has produced nine studies (Fig. 3) that investigate contaminants associated with plastic pollution. They demonstrate that plastics litter and microplastics have the potential to sorb an extended range of contaminants. Plastics thus can act as scavengers and transporters of trace metals and metalloids ${ }^{\mathbf{8 5 - 8 7}}$ and Persistent Organic Pollutants or POPs, ${ }^{\mathbf{8 8}}$ and these contaminants have the potential to be bioavailable to marine organisms upon ingestion. ${ }^{\mathbf{8}}$ Despite this evidence, some authors argue that the role of microplastic as a vector for toxic substances may be relatively small when compared to other exposure pathways, ${ }^{\mathbf{8 9}}$ and that the risk associated with MP acting as a vector for chemical pollutants (persistent organic pollutants and/or additive chemicals) to accumulate in organisms is low. ${ }^{90,91}$ However, most of the studies have focused on quantifying sorption rates considering the affinity of chemicals in isolation. The interaction and synergistic/antagonistic effect in complex systems need to be considered in further studies. ${ }^{\mathbf{2}}$

Australia has contributed one paper (Fig. 2) that explored the use of plastic pellets to quantify the distribution of POPs. ${ }^{93}$ Another was developed to detect plastic contaminants in wildlife using a simple non-destructive technique involving swabbing followed by gas chromatography-mass spectrometry. ${ }^{31}$

\subsection{Effects}

Australia has contributed significantly to our understanding of the impacts of derelict fishing nets in the aquatic environment (Fig. 2). Between 2003 and 2008, 2305 nets were collected from the Arafura and Timor Seas, and $89 \%$ of these were identified as originating from outside Australian waters. ${ }^{44}$ It was estimated that $2 \%$ of derelict nets resulted in entanglements ${ }^{94}$ and other papers have examined the rate at which nets degenerate, ${ }^{95}$ and one has examined the supply chain for foreign nets. ${ }^{96}$ Neither the UK nor Chinese literature examined entanglements caused by fishing nets.

Scientists from the UK (Fig. 3) have investigated the effects of plastic on fish ${ }^{97}$ and crustaceans. ${ }^{98}$ The Common Roach, Rutilus rutilus from the River Thames was examined, and larger fish were found to contain more pieces of plastic than smaller ones. ${ }^{97}$ The effect of plastic exposure and ingestion on Nephrops norvegicus was decreased feeding rate, body mass, and metabolic rate as well as reduced catabolism of stored lipids in animals with higher exposure rates. ${ }^{98}$

A number of papers concerned with the toxicological effects of plastic are written in the Chinese language and not readily available to English language readers (Fig. 4). In general, their work has investigated the toxicity of plastic to biota in aquatic environments, ${ }^{99}$ anthracene toxicity, ${ }^{\mathbf{1 0 0}}$ immune gene expression of rainbow trout, ${ }^{101}$ bioaccumulation and environmental fate of phenanthrene, ${ }^{\mathbf{1 0 2}}$ and the combined toxicity of MPs and pesticide pollution. ${ }^{103}$ This work represents a valuable resource that should be made available to the rest of the plastics research community. In order to make past Chinese language papers available they could be published in a special edition of Chinese works in English and future papers could include an English abstract.

As plastic reduces in size, its potential to accumulate and translocate within the tissues of organisms can increase. Research has demonstrated that the physical properties of plastic particles affect the ingestion and translocation of microplastics in bivalves. ${ }^{\mathbf{1 0 3}}$ Controlled laboratory exposures have been implemented to understand the uptake, ingestion, distribution and biological effects in organisms exposed to MPs. ${ }^{104,105}$ The most common particles analysed in laboratory experiments of MP include polylactic acid (PLA), high-density polyethylene (HDPE) and polystyrene (PS). This work has resulted in a better understanding of the interactions between MP and biota, ${ }^{103,106-111}$ although frequently studies use much higher concentrations of plastics than are typically found in the environment, and do not use aged or weathered materials of the type found in natural systems. ${ }^{\mathbf{1 0 4 , 1 1 2}}$

\subsection{Governance}

The "governance" category includes action taken by community groups, governance, management, knowledge and a small number of papers concerned with economics, emissions, reports, wastewater treatment plants and one on weather balloons. ${ }^{113}$ Australia has contributed the highest number of published documents on the "governance" category (Fig. 2), 
mostly around community action. These reports summarise the activities and outputs of citizen scientists. Australia's leading Citizen Science group is Tangaroa Blue (https:// www.tangaroablue.org/), who host the Australian Marine Debris Initiative, a program where citizens involved in environmental clean-up events can upload their field data to a public database. Metadata include the date, the number of participants and the length of the beach cleaned. Tangaroa blue also works with organisations such as Keep Australia Beautiful (https://kab.org.au/), various councils, natural resource management groups, and State government departments. The Marine Conservation Society (https://www.mscuk.org/) is the broad equivalent in the UK and has also contributed annual reports via an extensive range of citizen beach cleans. In China, there are in the order of 190 environmental groups that are concerned with ocean protection. One of the main groups is the Shanghai Rendu Ocean NGO Development Centre (http:// www.chinadevelopmentbrief.cn/directory/rendu-ocean-npodevelopment-center/). This was established in 2007 and registered as a private non-enterprise unit in 2013. Its long-term development goal is to become the most professional public welfare organisation in the field of marine garbage environmental protection in China.

Papers concerned with governance have a variety of foci (Fig. 2-4). Governance papers from Australia tend to focus on the threat of plastic to wildlife. The Australian Government's Environment Protection and Biodiversity Conservation (EPBC) Act 1999 and its "Threat Abatement Plan for the Impacts of Marine Debris on Vertebrate Wildlife of Australia's Coasts and Oceans" ${ }^{114}$ contribute to the way research is driven in Australia. For example, Maguire et al. ${ }^{115}$ explore changes in policies affecting the use of single-use plastic. China has two papers examining the effects of plastics on people, ${ }^{\mathbf{1 1 6 , 1 1 7}}$ one on the impacts on fisheries ${ }^{\mathbf{1 1 8}}$ and one concerned with wildlife impacts. ${ }^{119}$ In general, the governance papers are concerned with summarising the threat of marine plastic debris and finding solutions to the problem.

There have been numerous papers on the governance and management of plastic waste from all three countries (ESI, Table S1 $\dagger$ ). Typically, these focus on the efficiency of waste management strategies, and increasingly on the effectiveness of measures brought in to reduce plastic usage (e.g. assessing the impact of charging for single-use plastic carrier bags on the usage of such items ${ }^{\mathbf{1 2 0}}$ ).

\subsection{Physical processes}

Relatively few studies (to the end of 2019) have considered physical processes that distribute plastics across the ocean and around the world or across the land-sea interface from these countries (Fig. 2-4). The Australian contribution includes work which models the distributions of marine plastic debris. ${ }^{\mathbf{1 2 1}, \mathbf{1 2 2}}$ Pearce et al. ${ }^{123}$ explored the movement of drifter cards; Reissier et $a .^{\mathbf{1 2 4}}$ estimated plastic abundance around Australia.

China has produced one paper that looks at the rate at which plastic moves from the land to the sea $^{\mathbf{1 2 5}}$ and considers the possibility of reducing $\mathrm{CO}_{2}$ emissions by improving the processes of effective recycling and waste management of existing plastic. ${ }^{\mathbf{1 2 6}}$ The oceanic distribution of plastics has also been explored. ${ }^{127}$

Scientists in the UK also have explored the inclusion of plastics in the stratigraphic signal that defines the base of the Anthropocene. ${ }^{\mathbf{1 2 8}}$ Other materials such as artificial radionuclides (particularly isotopes of plutonium, $\mathrm{Pu}$ ), pesticide residues, enhanced fly ash levels, and concrete fragments also contribute to (or have been proposed as markers for) this signal. ${ }^{128}$ Additionally, research has been conducted into the potential trapping of microplastics in the intertidal zone ${ }^{66}$ and the effect of wind transport on macroplastic deposition and resuspension. ${ }^{\mathbf{1 2 9}}$ Terrestrial and riverine plastic debris has received less attention, although there are studies comparing abundance before and after flooding events (Hurley et al. 2018) 74 $^{7}$ and reviewing plastic debris on catchment scales. ${ }^{\mathbf{1 3 0}}$

\subsection{Review}

There have been several review papers published by scientists from the three regions (Fig. 2-4), which mostly reflect the respective research focus areas of each country. Seven of the nine reviews from China were conducted in 2019, focusing on toxicology, substrates, management of plastics, and contaminants. Australia has 13 review papers examining a wide range of topics including biotic interactions, human influences, and management impacts. There were five review papers from the UK, four of which assessed existing research on present threats of marine pollution in the region and one on seabirds. Although the overall focus of the review papers is about plastics, the papers also summarise the expertise being developed in the three countries.

\subsection{Techniques}

When examining environmental plastic debris, Australia, China, and the UK apply various sampling, separation, and analysis techniques. These include grab sampling, ${ }^{\mathbf{1 3 1}}$ surface water and surface microlayer sampling, ${ }^{\mathbf{6 6 , 1 2 4}}$ density separation, ${ }^{79}$ chemical digestion, ${ }^{68}$ visual identification, ${ }^{29}$ and chemical characterisation. ${ }^{61}$ Contamination mitigation measures (during sampling, separation and analysis, e.g. through use of exposed filter papers, procedural blanks and other controls) are also varied, with recent articles (e.g. Teng et $a .^{132}$ ) often reporting more details than early studies (e.g. Zhou et al. ${ }^{23}$ ). A detailed examination of techniques used to examine plastics associated with beaches indicates the degree of the problem (ESI Table S2 $\dagger$ ). Variability in methods included sampling frequency, location, area sampled, materials collected, size categories, colour categories and polymer identification techniques. Some of these differences were driven by the pursued question, such as contaminants on beached pellets $v s$. abundance of plastics. However, one of the key features of beaches that were repeatedly sampled was the strandline, representing the recent arrival of plastic. Using this beach compartment to assess standing stock and arrival rates/turnover would enable comparisons, especially if standard $(50 \times 50 \mathrm{~cm})$ quadrats were used. 
China has developed more independent procedures than Australia and the UK, many of which are published in papers not available in the English language. This work has concentrated on management and sampling, but also includes innovative work on the use of LIDAR to detect plastic in beach sand. ${ }^{133}$ The UK has produced papers describing innovative sampling and separation techniques, such as a method of sampling the sea surface microlayer for $\operatorname{MPs}^{66}$ and a novel sediment-microplastic isolation unit. $^{55}$

\section{Knowledge gaps (the "known unknowns"), and recommendations for monitoring and standardisation}

Plastic in the environment is potentially highly damaging and is recognised as such by most individuals and organisations. As a result, the scientific community has embraced the need to understand the scale of the problem and find appropriate solutions. However, plastic research, particularly on microplastics, is still being developed. Despite coming about in the age of rapidly developing technology, we lack time-tested methodologies that can be implemented effectively and reliably across the diversity of environmental gradients, cultures and languages. Studies on "beaches" (ESI Table S2†) should be relatively simple compared to others that require ship time and extensive lab access. However, unifying methods in this relatively simple environment is still challenging, with a need to standardise regarding the size and location of sampling areas, periodicity of sampling, depth of sampling and polymer identification methods. The identification of key sampling elements in each discipline will facilitate the development of standard methods. For beaches, the strandline was a common element (ESI Table S2 $\dagger$ ) that could be better exploited. Adopting standard $50 \times 50 \mathrm{~cm}$ quadrats on strandlines would enable more direct comparisons between regions and countries. Such methodologies create comparable and robust datasets, ${ }^{9}$ which allow us to assess patterns in plastic distribution, the processes driving these patterns and the environmental and societal impacts.

This synoptic review of published literature has identified clear differences in the areas of research targeted by each country and the methods used (Fig. 2-4), resulting in relatively sparse data that can be used to provide direct and systematic comparisons between contamination levels in different media or environments in each country. Rather than clearly demonstrating pollution gradients (e.g. Tables 2 and 3), the literature highlights a bias in research priorities driven by funding, government priorities and academic areas of interest, restricting comparisons among countries. The greatest research effort (33\%) has been studying plastic in substrates such as water and sediment, with more than half of these papers coming from China. The variety of sampling, separation and analytical techniques applied in environmental studies make data comparisons difficult due to the influence of methodological differences (Section 4.2, ESI Table S2 $\dagger$ ). These differences are compounded by conflicting plastic definitions, exclusion criteria and contamination protocols, stimulated by a rapidly developing research field with few standardised operational parameters. Overall there is a lack of consistency among papers in metrics and terminology used that needs to be rectified, as well as standardised sampling designs. ${ }^{134}$ There are also various definitions of "microplastic" in use, with the most common upper limits being either $5 \mathrm{~mm}$ or $1 \mathrm{~mm}$. Lower limits are less consistently defined if they are used at all. With the development of the term (and research into) 'nanoplastic', a consistent lower bound limit for MP reporting is essential. Superimposed upon these issues is the presence of a language barrier impeding the transfer of information (i.e. some publications used in this study are available only in the Chinese language with an English abstract, e.g. Cai et al. ${ }^{\mathbf{1 0 0}}$ ).

This TransPlas paper has identified some of the expertise developed in each county on plastics research. It provides us opportunities for international comparative studies with leadership from each region in their areas of expertise and sharing of developed techniques. For example, the technique developed in the UK to sample plastic in the surface microlayer draws on their expertise and experience in quantifying other surface microlayer contaminants. Adopting this method in Australia, China, and other countries will allow direct comparisons between countries and coastlines. For biotic assessments, examining sentinel species will also expedite our ability to study gradients by reducing the influence of different species-specific traits, which are thought to impact exposure rates. ${ }^{\mathbf{1 3 5}}$ This concept has been discussed previously for widely dispersed populations such as mussels, ${ }^{136}$ Procelleformes birds ${ }^{27}$ and sardines. ${ }^{137}$ The selection of sentinel species needs to be undertaken carefully. Sardines are ubiquitous fish that consume a wide range of prey, making them an excellent fish species to target. ${ }^{137}$ However, it can be more difficult to select sentinel bird species, as each can have a discrete distribution. For birds, it may be more useful to compare between functional groups. To compare plastic concentrations internationally, we recommend adopting a comprehensive framework of sampling methods (e.g. surface water, sediment, biota) based on the latest technical developments and recommendations. ${ }^{\mathbf{9 , 1 7 , 1 3 4 , 1 3 8}}$ Results from these efforts would provide evidence to compare pollution levels and determine if there is a gradient in different MP and macroplastic components to enable more effective source and flux calculations, and management approaches. TransPlas marks the beginning of relationship between individuals, institutions and countries to discuss these issues and resolve barriers while sharing protocols. Barriers such as access to resources, facilities and funding can be reduced through international collaborative programs which result in greater access to funding, sharing of resources and analytical capacity. An example of this is the "Life Below Water: Using Fish as Global Indicators of Microplastics” program (https://wun.ac.uk/ wun/research/view/life-below-water-using-fish-as-globalindicators-of-microplastics/).

The three most studied aspects of aquatic plastic pollution in Australia, the UK and China are "substrates", particularly sediment and water, followed by "biota" and "governance". China's focus on substrates has contributed to its substantial 
increase in its publication rate in 2018 and 2019. This increase has coincided with the implementation of the National Sword Policy of China to reduce the importation of international plastic waste. The policy signifies how China is interacting with the international community and its impact on other countries. Despite its focus on substrates, Australia is lagging behind China and the UK in terms of understanding where plastic is in its environment. This is made difficult due to its expansive unpopulated coast; however, this should provide an opportunity to explore marine-derived plastic pollution without the influence of contributing local sources.

The population size, density, and culture of each region (Table 4) has potentially driven research priorities. Scientists from the UK and China were more likely to examine the effects of plastic on commercially important species such as langoustines, ${ }^{26,98}$ mussels ${ }^{24,64}$ and oysters ${ }^{\mathbf{1 3 2}}$ than Australia-based scientists. Aquaculture is a significant part of the food chain in highly populated regions such as China and the UK. China produced more farmed food fish than the rest of the world combined in 2016, as it has done every year since 1991, with more from aquaculture than wild-caught fish since $1993 .{ }^{139}$ In 2016, China's production of live weight aquaculture products was 49244000 tons, while Australia produced 97000 tons. ${ }^{139}$ The small aquaculture industry in Australia and the expansive unpopulated coast suggest that plastic in aquaculture is not a significant threat in Australia. However, aquaculture is an essential component of China's food security, ${ }^{139}$ and as a result, perceived threats such as plastic pollution are likely to receive more attention.

Publications focussed on "biota" from Australia have concentrated on sea birds and other large organisms, including seals, sea lions and cetaceans. Seals, sea lions and cetaceans are protected in Australia (http://www.environment.gov.au/marine/ marine-species) and only a few sea bird species are harvested (during very limited, licensed, periods). While work on aquatic species with commercial benefit or which provide a pathway to human intake (from human health risk assessment) is essential, birds are considered biological indicators and sentinel organisms for ocean plastic contamination. ${ }^{\mathbf{1 7}}$ Birds are a valuable source of knowledge on plastic pollution, given their ability to migrate over large areas of the globe. The main bird groups to be studied have been Procellariiformes, followed by Suliformes and Charadriiformes. Most of the research has been conducted on carcasses of birds from natural mortality events such as wrecks and bycatch from fisheries. Other studies have used emetics and burrow surveys to investigate live birds. There are problems associated with each of these methods, ${ }^{\mathbf{1 3 4}}$ but used in conjunction these data are a resource for monitoring the plastic intake of birds and the health of the ocean, especially for threatened species. Flesh-footed shearwaters breed on islands around Australia but migrate to the Bay of Bengal and the North Pacific during the northern summer, providing an opportunity to use the same species to investigate plastic pollution in multiple locations.

To make international comparisons using birds we need to classify them according to their feeding behaviour. Surface feeders should differ in their plastic intake compared to deep divers due to their exposure. Classifying bird species this way will allow us to compare between ocean basins where different species occur. This would make comparisons between birds such as the flesh-footed shearwater which is listed as "near threatened", and the European Northern Fulmar which is listed as "endangered" more appropriate.

Australia has also developed considerable expertise in the effects of discarded nets ${ }^{\mathbf{4 4 , 9 5 , 9 6 , 1 4 0 , 1 4 1}}$ through the Commonwealth Scientific and Industrial Research Organisation (CSIRO). GhostNets Australia (GNA) has also made a valuable contribution by providing Indigenous people in northern Australia with a mechanism to record the arrival of nets on their shores. GNA has contributed to quantifying the scale and distribution of gear loss, which establishes a benchmark for monitoring and evaluating future mitigation measures.

One area of investigation that has been lacking in all three countries is linking aquatic plastic debris with human health. ${ }^{\mathbf{1 , 2}}$ In 2015 there was an Australian Parliamentary enquiry into the potential toxic impacts of plastic on humans which concluded that this was an area of research that the government should be actively pursuing. ${ }^{\mathbf{1 4 2}}$ Knowledge of the toxicity of MP through ingestion or inhalation is limited. ${ }^{\mathbf{1 4 3}}$ While we are beginning to elucidate the quantity of plastic in commercially important species, we are not yet developing an understanding of how much is transferred into humans. This is potentially important for chemicals that are added to plastics such as bisphenol A and phthalates, which are known endocrine disruptors. ${ }^{\mathbf{1 4 4}}$ Studies that integrate plastic transfer between trophic layers with humans as the endpoint are required to fully understand the effects of plastic. Comparisons between Australia, the UK and China would represent a gradient in terms of population size, pollution levels and relative reliance on aquaculture to investigate this issue.

Table 4 Population and geographic statistics for Australia, the UK and China. Data compiled from national databases from Australia, the UK and China

\begin{tabular}{lllll}
\hline & Population size $(\#)$ & $\begin{array}{l}\text { Population density } \\
\left(\# \mathrm{~km}^{2}\right)\end{array}$ & $\begin{array}{l}\text { Length of coast } \\
(\mathrm{km})\end{array}$ & $\begin{array}{l}\text { Number of people } \\
\text { per km of coast }\end{array}$ \\
\hline Australia & $25665622^{a}$ & $\sim 3$ & $35821^{b}$ & 716 \\
United Kingdom & $66435600^{c}$ & 274 & $17820^{d}$ & 17820 \\
China & $1400050000^{e}$ & 146 & $18000^{f}$ & 77780
\end{tabular}

${ }^{a}$ Australian Bureau of Statistics (population clock 22/04/2020). ${ }^{b}$ Geosciences Australia. ${ }^{c}$ UK Office for National Statistics (June 2018). ${ }^{d}$ Ordnance Survey UK. ${ }^{e}$ National Bureau of Statistics China. ${ }^{f}$ National Geomatics Centre of China. 


\section{Forward look}

Research focus and intensity on macro- and microplastics vary between Australia, China and the UK. This reflects both funding and research priorities, and the size of the populations. China has been very proactive in recent years, reflecting the size of the potential plastics problem, food security and its large population. Scientists are working towards understanding the threat to protein sources, aquatic environments and the potential for sediments in water bodies to retain plastic debris.

Australia, especially southern Australia, faces challenges that are significantly different to both the UK and China. The small population, long coast, and few rivers on the west and south coasts mean that plastic debris accumulates and is likely to originate elsewhere. The minimal contribution to aquatic plastic pollution by Australia is evident in the data shown in Lebreton et al..$^{15}$ Australia faces an additional problem in that its southern coast is at approximately $35^{\circ}$ south, is $\sim 3000 \mathrm{~km}$ long, and coincides with the approximate latitude of the "Garbage Patch Belt" (GPB) of the southern hemisphere. ${ }^{145}$ The likely interaction of the coast with the GPB potentially makes it a valuable coast to use for the monitoring of local $v s$. oceanic supply of plastics and the removal of MP from the ocean. In effect, plastic debris emitted from rivers of South East Asia that circulate the Indian Ocean or are transported along the Leeuwin Current may, over time (years to decades, depending on oceanic circulation), transit the south coast of Australia. Here, Australia's Citizen Science program is highly valuable, given the expansive unpopulated coast. The benefits of citizen science include the ability of individuals to understand and study 'their' coast, noting that the scientific quality of citizen science projects is highly dependent on the development of a coherent and thorough sampling protocol, and the education of the citizens involved. ${ }^{\mathbf{1 4 6 , 1 4 7}}$ Tangaroa Blue has become the focus for Australia Citizen Scientists and has unified the method used in quantifying beach debris, including plastic. The contribution of citizens will be invaluable in the future as some parts of the coast are expected to become highly polluted by plastic due to this regional oceanography. ${ }^{\mathbf{1 4 5}}$ Further work needs to be undertaken to describe the baseline data for Australia, which will need to include more work by Citizen Scientists with additional work from Scientists.

The UK has a very high population density and long coastline (particularly in heavily urbanised or industrialised estuaries), and significant amounts of legacy coastal brownfield land and landfill sites. ${ }^{148}$ Here, it is valuable for researchers to concentrate on the processes linking leakage of plastic material from the human environment to the coastal environment, such as work in estuaries and the lower courses of rivers. In addition, due to the extensive use of combined sewer systems, processes of potential labelling of plastics with wastewater-derived (and other) contaminants need further assessment. The UK has established protocols through its contaminated land risk management framework, which embeds consideration of contaminant linkages in risk management. In this framework, a receptor (which could be adversely affected by the contamination) is linked to the contaminant source by one or more pathways - all three components (of this source-pathwayreceptor or $\mathrm{S}-\mathrm{P}-\mathrm{R}$ linkage) are required for a risk to be present. A risk management intervention can take place at any point in the $\mathrm{S}-\mathrm{P}-\mathrm{R}$ linkage if it breaks the linkage. The source may be removed, the pathway intercepted, or the receptor behaviour or location modified. Considering this model for plastics contamination (see also Waldschläger et $a l .{ }^{\mathbf{1 4 9}}$ ), source management interventions such as bans, increasing recycling etc., can be combined with pathway management (plastics recovery or interception, settling or removal in "sinks"150) to reduce the risk to the receptor or receiving environment. These interventions are best made where contaminant concentrations are highest (e.g. in estuaries and coasts), to reduce both flux and risk. However, better information on sources and pathways, including particle numbers and fluxes, are required to effectively target actions and interventions.

Quantitative and comparable methods of environmental sampling and analysis to assess source management or pollution reduction initiatives are required to compare between countries. However, to achieve this, we need to develop beyond "spot" samples (in time and space), to internationally based strategic sampling strategies and protocols (e.g., ${ }^{138,151}$ and ISO/ CD 24187.2, the latter is currently under development, see also https://wun.ac.uk/wun/research/view/life-below-waterusing-fish-as-global-indicators-of-microplastics/) where standardised methods and key indicator species are used to elucidate the problem comparably. Thus, enabling us to assess the impact of plastic pollution across the globe. The role of TransPlas is to develop strong relationships between the three countries to achieve these goals. This paper serves as the first step in building relationships between researchers and their institutions and indicates which expertise each country has most developed.

\section{Conclusions}

Research on plastic debris in the ocean has arguably followed a predictable path up to now. Plastic began to appear in the environment, it was recognised as a problem, it was studied, and policies have been developed. However, to effectively manage the problem, we need to converge on standardised methods and bioindicator species, as well as build a more developed understanding of the physical processes driving the distribution patterns we see in different habitats to make global comparisons more reliable. To achieve this, we need to adopt global frameworks such as the Integrated Marine Debris Observing System (IMDOS) proposed by Maximenko and others, ${ }^{9}$ which responds to the policies and recommendation of international bodies such as the United Nations and many other notable organisations and programs. But, we also need to make use of expertise from different countries, organisations and individuals who have developed skills in specific areas. This study has demonstrated how the different requirements of each country examined (i.e. Australia, the UK and China) have defined the skills developed. China has advanced its knowledge of plastic pollution levels in the water column and seabed in 
addition to following the path of contaminants into biota, Australia has a well-developed program on birds and Citizen Science and the UK is leading in dynamics in the coast and estuaries, and zooplankton.

This review has identified some of the most commonly used metrics and key variables that should be included in investigations in the future. In terms of reporting data, the range for the number of items per unit, mean and median (individual, mass, area or volume) and the frequency of occurrence (FO) should be considered the minimum descriptive statistics that are included in every study.

There are also substantial differences in the way Australia and China have responded to the plastics problem. China has a dominantly top-down approach with the government promoting changes in their relationship with plastic on the industrial and individual scale. In contrast, Australia appears to be driven by a bottom-up approach with community groups and businesses responding to the problem quickly. There are benefits to both types of programs, and the best of each needs to be explored and adopted.

Unlike organisms, plastic particles do not have geographic or substrate boundaries, making them the most widely distributed solid contaminant on the planet. For this reason, the need for consistency in methods and reporting across international boundaries is paramount. The TransPlas goal is to unify methods used in Australia, the UK and China, to provide comparable data for international comparison and assessment. Still, we will be working towards goals defined by international organisations such as the United Nations Environment Program. In the Decade of Ocean Science for Sustainable Development, we will endeavour to contribute to the Sustainable Development Goals outlined in target 14.1 and follow the directives outlined in GESAMP $99 .{ }^{138}$

\section{Conflicts of interest}

There are no conflicts to declare.

\section{Acknowledgements}

The authors acknowledge the support of the University of Southampton, via a Global Research Initiator award, and the University of Western Australia's contribution via a Research Collaboration Award in developing the work presented in this paper. AC also acknowledges support from the Hong Kong Branch of Southern Marine Science and Engineering Guangdong Laboratory (Guangzhou) in his contribution to this paper. LY and XZ were supported by the National Key Research and Development Program of China (2018YFC1406604).

\section{References}

1 S. Sharma and S. Chatterjee, Microplastic pollution, a threat to marine ecosystem and human health: a short review, Environ. Sci. Pollut. Res., 2017, 24, 21530-21547.

2 L. G. A. Barboza, A. Dick Vethaak, B. R. B. O. Lavorante, A. K. Lundebye and L. Guilhermino, Marine microplastic debris: An emerging issue for food security, food safety and human health, Mar. Pollut. Bull., 2018, 133, 336-348.

3 D. Tickner, J. J. Opperman, R. Abell, M. Acreman, A. H. Arthington, S. E. Bunn and L. Young, Bending the curve of global freshwater biodiversity loss: An emergency recovery plan, BioScience, 2020, 70, 330-342.

4 V. Fischer, N. O. Elsner, N. Brenke, E. Schwabe and A. Brandt, Plastic pollution of the Kuril - Kamchatka Trench area (NW Pacific), Deep Sea Res., Part II, 2015, 111, 399-405.

5 S. Allen, D. Allen, V. R. Phoenix, G. Le Roux, P. Durántez Jiménez, A. Simonneau, S. Binet and D. Galop, Atmospheric transport and deposition of microplastics in a remote mountain catchment, Nat. Geosci., 2019, 12, 339-344.

6 F. Pohl, J. T. Eggenhuisen, I. A. Kane and M. A. Clare, Transport and burial of microplastics in deep-marine sediments by turbidity currents, Environ. Sci. Technol., 2020, 54, 4180-4189.

7 J. Wang, L. Zheng and J. Li, A critical review on the sources and instruments of marine microplastics and prospects on the relevant management in China, Waste Manage. Res., 2018, 36, 898-911.

8 A. Cozar, F. Echevarria, J. I. Gonzalez-Gordillo, X. Irigoien, B. Ubeda, S. Hernandez-Leon, A. T. Palma, S. NavarroS, J. Garcia-de-Lomas, A. Ruiz, M. L. Fernandez-de-Puelles and C. M. Duarte, Plastic debris in the open ocean, Proc. Natl. Acad. Sci. U. S. A., 2014, 111, 10239-10244.

9 N. Maximenko, P. Corradi, K. L. Law, E. Van Sebille, S. P. Garaba, R. S. Lampitt and C. Wilcox, Toward the Integrated Marine Debris Observing System, Front. Mar. Sci., 2019, 6, 447.

10 GESAMP, Sources, Fate and Effects of Microplastics in the Marine Environment (Part 1), United Nations Environment Programme (UNEP) Printed, 2015.

11 Z. L. R. Botterell, N. Beaumont, T. Dorrington, M. Steinke, R. C. Thompson and P. K. Lindeque, Bioavailability and effects of microplastics on marine zooplankton: A review, Environ. Pollut., 2019, 245, 98-110.

12 M. Eriksen, L. C. M. Lebreton, H. S. Carson, M. Thiel, C. J. Moore, J. C. Borerro, F. Galgani, P. G. Ryan and J. Reisser, Plastic pollution in the world's oceans: more than 5 trillion plastic pieces weighing over 250,000 tons afloat at sea, PLoS One, 2014, 9(12), e111913.

13 E. Van Sebille, C. Wilcox, L. Lebreton, N. Maximenko, B. D. Hardesty, J. A. Van Franeker, M. Eriksen, D. Siegel, F. Galgani and K. L. Law, A global inventory of small floating plastic debris, Environ. Res. Lett., 2015, 10, 124006.

14 K. Pabortsava and R. S. Lampitt, High concentrations of plastic hidden beneath the surface of the Atlantic Ocean, Nat. Commun., 2020, 11, 4073.

15 L. C. M. Lebreton, J. Zwet Van Der, J. Damsteeg, B. Slat, A. Andrady and J. Reisser, River plastic emissions to the world's oceans, Nat. Commun., 2017, 8, 15611.

$16 \mathrm{~W}$. Wang and J. Wang, Investigation of microplastics in aquatic environments: An overview of the methods used, 
from field sampling to laboratory analysis, Trends Anal. Chem., 2018, 108, 195-202.

17 J. F. Provencher, S. B. Borrelle, A. L. Bond, J. L. Lavers, J. A. van Franeker, S. Kühn, S. Hammer, S. Avery-Gomm and M. L. Mallory, Recommended best practices for plastic and litter ingestion studies in marine birds: Collection, processing, and reporting, Facets, 2019, 4, 111-130.

18 H. Wickham, ggplot2: Elegant Graphics for Data Analysis, Springer-Verlag, New York, 2016.

19 R Core Team, A Language and Environment for Statistical Computing, R Foundation for Statistical Computing, Vienna, Austria, 2019, https://www.R-project.org/.

$20 \mathrm{~J}$. A. Ivar do Sul and M. F. Costa, The present and future of microplastic pollution in the marine environment, Environ. Pollut., 2014, 185, 352-364.

21 M. H. Wang, Y. He and B. Sen, Research and management of plastic pollution in coastal environments of China, Environ. Pollut., 2019, 248, 898-905.

22 Q. Yu, X. Hu, B. Yang, G. Zhang, J. Wang and W. Ling, Distribution, abundance and risks of microplastics in the environment, Chemosphere, 2020, 249, 126059.

23 P. Zhou, C. Huang, H. Fang, W. Cai, D. Li, X. Li and H. Yu, The abundance, composition and sources of marine debris in coastal seawaters or beaches around the northern South China Sea (China), Mar. Pollut. Bull., 2011, 62, 1998-2007.

24 J. Li, X. Qu, L. Su, W. Zhang, D. Yang, P. Kolandhasamy, D. Li and H. Shi, Microplastics in mussels along the coastal waters of China, Environ. Pollut., 2016, 214, 177-184.

25 N. A. Welden, B. Abylkhani and L. M. Howarth, The effects of trophic transfer and environmental factors on microplastic uptake by plaice, Pleuronectes plastessa and spider crab, Maja squinado, Environ. Pollut, 2018, 239, 351-358.

26 F. Murray and P. R. Cowie, Plastic contamination in the decapod crustacean Nephrops norvegicus (Linnaeus, 1758), Mar. Pollut. Bull., 2011, 62, 1207-1217.

27 L. Roman, E. Bell, C. Wilcox, B. D. Hardesty and M. Hindell, Ecological drivers of marine debris ingestion in Procellariiform Seabirds, Sci. Rep., 2019, 9, 916.

28 L. Roman, H. Paterson, K. A. Townsend, C. Wilcox, B. D. Hardesty and M. A. Hindell, Size of marine debris items ingested and retained by petrels, Mar. Pollut. Bull., 2019, 142, 569-575.

29 J. L. Lavers, J. C. Hodgson and R. H. Clarke, Prevalence and composition of marine debris in Brown Booby (Sula leucogaster) nests at Ashmore Reef, Mar. Pollut. Bull., 2013, 77, 320-324.

30 H. L. Paterson and J. N. Dunlop, Minimal plastic in FleshFooted Shearwater Ardenna Carneipes burrows at Southwestern Australia colonies, Mar. Ornithol., 2018, 167, 165-167.

31 B. D. Hardesty, D. Holdsworth, A. T. Revill and C. Wilcox, A biochemical approach for identifying plastics exposure in live wildlife, Methods Ecol. Evol., 2015, 6, 92-98.

32 N. J. O'Hanlon, A. L. Bond, J. L. Lavers, E. A. Masden and N. A. James, Monitoring nest incorporation of anthropogenic debris by Northern Gannets across their range, Environ. Pollut., 2019, 255, 113152.

33 C. Zhu, D. Li, Y. Sun, X. Zheng, X. Peng, K. Zheng, B. Hu, $\mathrm{X}$. Luo and B. Mai, Plastic debris in marine birds from an island located in the South China Sea, Mar. Pollut. Bull., 2019, 149, 110566.

34 Z. Feng, T. Zhang, Y. Li, X. He, R. Wang, J. Xu and G. Gao, The accumulation of microplastics in fish from an important fish farm and mariculture area, Haizhou Bay, China, Sci. Total Environ., 2019, 696, 133948.

35 S. Jahan, V. Strezov, H. Weldekidan, R. Kumar, T. Kan, S. A. Sarkodie, J. He, B. Dastjerdi and S. P. Wilson, Interrelationship of microplastic pollution in sediments and oysters in a seaport environment of the eastern coast of Australia, Sci. Total Environ., 2019, 695, 133924.

36 J. Li, D. Yang, L. Li, K. Jabeen and H. Shi, Microplastics in commercial bivalves from China, Environ. Pollut., 2015, 207, 190-195.

37 A. Ravn, Waste Sorting, A Proposed Social Design Workshop to Improve Behaviour and Management of Recycling, Linnaeus University, Sweden, 2018.

38 N. A. Welden and P. R. Cowie, Environment and gut morphology influence microplastic retention in langoustine, Nephrops norvegicus, Environ. Pollut., 2016, 214, 859-865.

39 F. Zhang, X. Wang, J. Xu, L. Zhu, G. Peng, P. Xu and D. Li, Food-web transfer of microplastics between wild caught fish and crustaceans in East China Sea, Mar. Pollut. Bull., 2019, 146, 173-182.

40 M. Mohsen, Q. Wang, L. Zhang, L. Sun, C. Lin and H. Yang, Microplastic ingestion by the farmed sea cucumber Apostichopus japonicus in China, Environ. Pollut., 2019, 245, 1071-1078.

41 M. Mohsen, Q. Wang, L. Zhang, L. Sun, C. Lin and H. Yang, Heavy metals in sediment, microplastic and sea cucumber Apostichopus japonicus from farms in China, Mar. Pollut. Bull., 2019, 143, 42-49.

42 R. Allen, D. Jarvis, S. Sayer and C. Mills, Entanglement of grey seals Halichoerus grypus at a haul out site in Cornwall, UK, Mar. Pollut. Bull., 2012, 64, 2815-2819.

43 Q. A. Schuyler, C. Wilcox, K. A. Townsend, K. R. WedemeyerStrombel, G. Balazs, E. van Sebille and B. D. Hardesty, Risk analysis reveals global hotspots for marine debris ingestion by sea turtles, Glob. Change Biol., 2016, 22, 567-576.

44 C. Wilcox, G. Heathcote, J. Goldberg, R. Gunn, D. Peel and B. D. Hardesty, Understanding the sources and effects of abandoned, lost, and discarded fishing gear on marine turtles in northern Australia, Conserv. Biol., 2015, 29, 198206.

45 Q. Schuyler, C. Wilcox, K. Townsend, B. D. Hardesty and N. J. Marshall, Mistaken identity? Visual similarities of marine debris to natural prey items of sea turtles, $B M C$ Ecol., 2014, 14, 14.

46 C. Wilcox, M. Puckridge, Q. A. Schuyler, K. Townsend and B. D. Hardesty, A quantitative analysis linking sea turtle mortality and plastic debris ingestion, Sci. Rep., 2018, 8, 12536. 
47 L. Reinhold, Absence of ingested plastic in 20 necropsied sea turtles in Western Australia, MTN, 2015, 144, 13-15.

48 N. M. Hall, K. L. E. Berry, L. Rintoul and M. O. Hoogenboom, Microplastic ingestion by scleractinian corals, Mar. Biol., 2015, 162, 725-732.

49 W. Courtene-Jones, B. Quinn, C. Ewins, S. F. Gary and B. E. Narayanaswamy, Consistent microplastic ingestion by deep-sea invertebrates over the last four decades (1976-2015), a study from the North East Atlantic, Environ. Pollut., 2019, 244, 503-512.

50 F. M. Windsor, R. M. Tilley, C. R. Tyler and S. J. Ormerod, Microplastic ingestion by riverine macroinvertebrates, Sci. Total Environ., 2019, 646, 68-74.

51 C. Muller-Karanassos, A. Turner, W. Arundel, T. Vance, P. K. Lindeque and M. Cole, Antifouling paint particles in intertidal estuarine sediments from southwest England and their ingestion by the harbour ragworm, Hediste diversicolor, Environ. Pollut., 2019, 249, 163-170.

52 M. Cole, P. Lindeque, E. Fileman, C. Halsband, R. Goodhead, J. Moger and T. S. Galloway, Microplastic ingestion by zooplankton, Environ. Sci. Technol., 2013, 47, 6646-6655.

53 M. Cole, P. Lindeque, C. Halsband and T. S. Galloway, Microplastics as contaminants in the marine environment: a review, Mar. Pollut. Bull., 2016, 62(12), 2588-2597.

54 M. Cole and T. S. Galloway, Ingestion of nanoplastics and microplastics by Pacific Oyster larvae, Environ. Sci. Technol., 2015, 49, 14625-14632.

55 R. L. Coppock, M. Cole, P. K. Lindeque, A. M. Queirós and T. S. Galloway, A small-scale, portable method for extracting microplastics from marine sediments, Environ. Pollut., 2017, 230, 829-837.

56 K. Evans and M. A. Hindell, The diet of sperm whales (Physeter macrocephalus) in southern Australian waters, ICES J. Mar. Sci., 2004, 61, 1313-1329.

57 A. L. Lusher, G. Hernandez-Milian, J. O'Brien, S. Berrow, I. O'Connor and R. Officer, Microplastic and macroplastic ingestion by a deep diving, oceanic cetacean: The True's beaked whale Mesoplodon mirus, Environ. Pollut., 2015, 199, 185-191.

58 S. E. Nelms, J. Barnett, A. Brownlow, N. J. Davison, R. Deaville, T. S. Galloway, P. K. Lindeque, D. Santillo and B. J. Godley, Microplastics in marine mammals stranded around the British coast: ubiquitous but transitory?, Sci. Rep., 2019, 9, 1075.

59 J. L. Lavers and A. L. Bond, Selectivity of flesh-footed shearwaters for plastic colour: Evidence for differential provisioning in adults and fledglings, Mar. Environ. Res., 2016, 113, 1-6.

60 H. R. Cousin, H. J. Auman, R. Alderman and P. Virtue, The frequency of ingested plastic debris and its effects on body condition of Short-tailed Shearwater (Puffinus tenuirostris) pre-fledging chicks in Tasmania, Australia, Emu, 2015, 115, 6-11.
61 M. Steer, M. Cole, R. C. Thompson and P. K. Lindeque, Microplastic ingestion in fish larvae in the western English Channel, Environ. Pollut., 2017, 226, 250-259.

62 L. I. Devriese, M. D. van der Meulen, T. Maes, K. Bekaert, I. Paul-Pont, L. Frère, J. Robbens and A. D. Vethaak, Microplastic contamination in brown shrimp (Crangon crangon, Linnaeus 1758) from coastal waters of the Southern North Sea and Channel area, Mar. Pollut. Bull., 2015, 98, 179-187.

63 R. W. Furness, Plastic particle pollution: Accumulation by procellariiform seabirds at Scottish Colonies, Mar. Pollut. Bull., 1985, 16, 103-106.

64 A. I. Catarino, V. Macchia, W. G. Sanderson, R. C. Thompson and T. B. Henry, Low levels of microplastics (MP) in wild mussels indicate that MP ingestion by humans is minimal compared to exposure via household fibres fallout during a meal, Environ. Pollut., 2018, 237, 675-684.

65 L. Zhu, H. Wang, B. Chen, X. Sun, K. Qu and B. Xi, Microplastic ingestion in deep-sea fish from the South China Sea, Sci. Total Environ., 2019, 677, 493-501.

66 Z. T. Anderson, A. B. Cundy, I. W. Croudace, P. E. Warwick, O. Celis-hernandez and J. L. Stead, A rapid method for assessing the accumulation of microplastics in the sea surface microlayer (SML) of estuarine systems, Sci. Rep., 2018, 8, 9428.

67 J. Ding, F. Jiang, J. Li, Z. Wang, C. Sun, Z. Wang, L. Fu, N. X. Ding and C. He, Microplastics in the coral reef systems from Xisha Islands of South China Sea, Environ. Sci. Technol., 2019, 53, 8036-8046.

68 J. Li, C. Green, A. Reynolds, H. Shi and J. M. Rotchell, Microplastics in mussels sampled from coastal waters and supermarkets in the United Kingdom, Environ. Pollut., 2018, 241, 35-44.

69 M. Di and J. Wang, Microplastics in surface waters and sediments of the Three Gorges, Sci. Total Environ., 2018, 616, 1620-1627.

70 S. Hajbane and C. B. Pattiaratchi, Plastic pollution patterns in offshore, nearshore and estuarine waters: A case study from Perth, Western Australia, Front. Mar. Sci., 2017, 4, 63.

71 R. R. Hurley, J. C. Woodward and J. J. Rothwell, Ingestion of microplastics by freshwater tubifex worms, Environ. Sci. Technol., 2017, 51, 12844-12851.

72 W. Courtene-Jones, B. Quinn, S. F. Gary, A. O. M. Mogg and B. E. Narayanaswamy, Microplastic pollution identified in deep-sea water and ingested by benthic invertebrates in the Rockall Trough, North Atlantic Ocean, Environ. Pollut, 2017, 231, 271-280.

73 A. L. Lusher, A. Burke, I. O. Connor and R. Officer, Microplastic pollution in the Northeast Atlantic Ocean: Validated and opportunistic sampling, Mar. Pollut. Bull., 2014, 88, 325-333.

74 R. Hurley, J. Woodward and J. J. Rothwell, Microplastic contamination of river beds significantly reduced by catchment-wide flooding, Nat. Geosci., 2018, 11, 251-257.

75 Z. Wang, B. Su, X. Xu, D. Di, H. Huang, K. Mei, R. A. Dahlgren, M. Zhang and X. Shang, Preferential 
accumulation of small $(<300 \mu \mathrm{m})$ microplastics in the sediments of a coastal plain river network in eastern China, Water Res., 2018c, 144, 393-401.

76 K. Zhang, X. Xiong, H. Hu, C. Wu, Y. Bi, Y. Wu, B. Zhou, P. K. S. Lam and J. Liu, Occurrence and characteristics of microplastic pollution in Xiangxi Bay of Three Gorges Reservoir, China, Environ. Sci. Technol., 2017, 51, 37943801 .

77 Y. Zou, Q. Xu, H. Zhang, Y. Wang, C. Liu, H. Zheng and F. Li, Review on the Joint Toxicity of Microplastics and Pesticide Pollution, Asian Journal of Ecotoxicology, 2017, 12, 25-33.

78 K. Zhang, W. Gong, J. Lv, X. Xiong and C. Wu, Accumulation of floating microplastics behind the Three Gorges Dam, Environ. Pollut., 2015, 204, 117-123.

79 Y. Fan, K. Zheng, Z. Zhu, G. Chen and X. Peng, Distribution, sedimentary record, and persistence of microplastics in the Pearl River catchment, China, Environ. Pollut., 2019, 251, 862-870.

80 K. Xiong, X. Zhao, Q. Zhou, C. Fu, C. Tu, L. Li and Y. Luo, The pollution characteristics of microplastics in the water and sediments of Sanggou bay in the Yellow Sea, Marine Environmental Science, 2019, 38, 198-204.

81 W. Zhang, X. Ma, Z. Zhang, Y. Wang, J. Wang, J. Wang and D. Ma, Persistent organic pollutants carried on plastic resin pellets from two beaches in China, Mar. Pollut. Bull., 2015, 99, 28-34.

82 L. Mai, L. Bao, L. Shi, L. Liu and E. Y. Zeng, Polycyclic aromatic hydrocarbons affiliated with microplastics in surface waters of Bohai and Huanghai Seas, China, Environ. Pollut., 2018, 241, 834-840.

83 Z. Wang, M. Chen, L. Zhang, K. Wang, X. Yu, Z. Zheng and R. Zheng, Sorption behaviors of phenanthrene on the microplastics identified in a mariculture farm in Xiangshan Bay, southeastern China, Sci. Total Environ., 2018, 628, 1617-1626.

84 X. Tan, X. Yu, L. Cai, J. Wang and J. Peng, Microplastics and associated PAHs in surface water from the Feilaixia Reservoir in the Beijiang River, China, Chemosphere, 2019, 221, 834-840.

85 K. Ashton, L. Holmes and A. Turner, Association of metals with plastic production pellets in the marine environment, Mar. Pollut. Bull., 2010, 60, 2050-2055.

86 L. A. Holmes, A. Turner and R. C. Thompson, Adsorption of trace metals to plastic resin pellets in the marine environment, Environ. Pollut., 2012, 160, 42-48.

87 A. Turner and K. S. Lau, Elemental concentrations and bioaccessibilities in beached plastic foam litter, with particular reference to lead in polyurethane, Mar. Pollut. Bull., 2016, 112, 265-270.

88 A. Bakir, S. J. Rowland and R. C. Thompson, Enhanced desorption of persistent organic pollutants from microplastics under simulated physiological conditions, Environ. Pollut., 2014, 185, 16-23.

89 T. Gouin, N. Roche, R. Lohmann and G. Hodges, A thermodynamic approach for assessing the environmental exposure of chemicals absorbed to microplastic, Environ. Sci. Technol., 2011, 45, 1466-1472.

90 A. A. Koelmans, A. Bakir, G. A. Burton and C. R. Janssen, Microplastic as a vector for chemicals in the aquatic environment: critical review and model-supported reinterpretation of empirical studies, Environ. Sci. Technol., 2016, 50, 3315-3326.

91 M. E. Hodson, C. A. Duffus-Hodson, A. Clark, M. T. Prendergast-miller and K. L. Thorpe, Plastic bag derived-microplastics as a vector for metal exposure in terrestrial Invertebrates, Environ. Sci. Technol., 2017, 51, 4714-4721.

92 A. Bakir, S. J. Rowland and R. C. Thompson, Competitive sorption of persistent organic pollutants onto microplastics in the marine environment, Mar. Pollut. Bull., 2012, 64, 2782-2789.

93 B. G. Yeo, H. Takada, H. Taylor, M. Ito, J. Hosoda, M. Allinson, S. Connell, L. Greaves and J. McGrath, POPs monitoring in Australia and New Zealand using plastic resin pellets, and International Pellet Watch as a tool for education and raising public awareness on plastic debris and POPs, Mar. Pollut. Bull., 2015, 101, 137-145.

94 M. M. Jones, Fishing debris in the Australian marine environment, Mar. Pollut. Bull., 1995, 30, 25-33.

95 M. K. Broadhurst and R. B. Millar, Reducing the marine debris of recreational hoop nets in south-eastern Australia, Mar. Pollut. Bull., 2017, 119, 40-47.

96 J. R. A. Butler, R. Gunn, H. L. Berry, G. A. Wagey, B. D. Hardesty and C. Wilcox, A Value Chain Analysis of ghost nets in the Arafura Sea: Identifying trans-boundary stakeholders, intervention points and livelihood tradeoffs, J. Environ. Manage., 2013, 123, 14-25.

97 A. A. Horton, M. D. Jürgens, E. Lahive, P. M. van Bodegom and M. G. Vijver, The influence of exposure and physiology on microplastic ingestion by the freshwater fish Rutilus rutilus (roach) in the River Thames, UK, Environ. Pollut., 2018, 236, 188-194.

98 N. A. C. Welden and P. R. Cowie, Long-term microplastic retention causes reduced body condition in the langoustine, Nephrops norvegicus, Environ. Pollut., 2016, 218, 895-900.

99 P. Zhang, Z. Yan, G. Lu and Y. Ji, Single and combined effects of microplastics and roxithromycin on Daphnia magna, Environ. Sci. Pollut. Res., 2019, 2, 17010-17020.

100 Y. Cai, J. Zhao, W. Li, W. Song, D. Zhang and X. Pan, Retention of polystyrene particles of different sizes in zebrafish gills and their effect on toxicity of anthracene to gill cells, Chinese Journal of Applied and Environmental Biology, 2017, 23, 17010-17020.

101 L. Cao, Y. Li, R. Liang, M. Wang and K. Li, Effects of microplastic particles on immune gene expression of rainbow trout, Acta Scientiae Circumstantiae, 2018, 38, 395-400.

102 Y. Ma, A. Huang, S. Cao, F. Sun, L. Wang and H. Guo, Effects of nanoplastics and microplastics on toxicity, bioaccumulation, and environmental fate of 
phenanthrene in fresh water, Environ. Pollut., 2016, 219, 166-173.

103 M. A. Browne, A. Dissanayake, T. S. Galloway, D. M. Lowe and R. C. Thompson, Ingested microscopic plastic translocates to the circulatory system of the mussel, Mytilus edulis (L.), Environ. Sci. Technol., 2008, 42, 50265031.

104 N. N. Phuong, A. Zalouk-Vergnoux, L. Poirier, A. Kamari, A. Châtel, C. Mouneyrac and F. Lagarde, Is there any consistency between the microplastics found in the field and those used in laboratory experiments?, Environ. Pollut., 2016, 211, 111-123.

105 E. M. Cunningham and J. D. Sigwart, Environmentally accurate microplastic levels and their absence from exposure studies, Integr. Comp. Biol., 2019, 59, 1485-1496.

106 A. J. R. Watts, C. Lewis, R. M. Goodhead, S. J. Beckett, J. Moger, C. R. Tyler and T. S. Galloway, Uptake and retention of microplastics by the shore crab Carcinus maenas, Environ. Sci. Technol., 2014, 48, 8823-8830.

107 A. I. Catarino, R. Thompson, W. Sanderson and T. B. Henry, Development and optimisation of a standard method for extraction of microplastics in mussels by enzyme digestion of soft tissues, Environ. Toxicol. Chem., 2017, 36, 947-951.

108 D. J. Hodgson, A. L. Bréchon and R. C. Thompson, Ingestion and fragmentation of plastic carrier bags by the amphipod Orchestia gammarellus: Effects of plastic type and fouling load, Mar. Pollut. Bull., 2018, 127, 154-159.

109 M. Cole, R. Coppock, P. K. Lindeque, D. Altin, S. Reed, D. W. Pond, L. Sørensen, T. S. Galloway and A. M. Booth, Effects of nylon microplastic on feeding, lipid accumulation, and moulting in a coldwater Copepod, Environ. Sci. Technol., 2019, 53, 7075-7082.

110 D. S. Green, T. J. Colgan, R. C. Thompson and J. C. Carolan, Exposure to microplastics reduces attachment strength and alters the haemolymph proteome of blue mussels (Mytilus edulis), Environ. Pollut., 2019, 246, 423-434.

111 S. Ziajahromi, A. Kumar, P. A. Neale and F. D. L. Leusch, Effects of polyethylene microplastics on the acute toxicity of a synthetic pyrethroid to midge larvae (Chironomus tepperi) in synthetic and river water, Sci. Total Environ., 2019, 671, 971-975.

112 E. E. Burns and A. B. A. Boxall, Microplastics in the aquatic environment: Evidence for or against adverse impacts and major knowledge gaps, Environ. Toxicol. Chem., 2018, 37, 2776-2796.

113 O. R. O'Shea, M. Hamann, W. Smith and H. Taylor, Predictable pollution: An assessment of weather balloons and associated impacts on the marine environment - An example for the Great Barrier Reef, Australia, Mar. Pollut. Bull., 2014, 79, 61-68.

114 Australian Government, Threat Abatement Plan for the Impacts of Marine Debris on the Vertebrate Wildlife of Australia's Coasts and Oceans, Department of the Environment and Energy, 2018, p. 53.

115 R. Maguire, H. Johnson, M. B. Taboada, L. Barner and G. A. Caldwell, A Review of Single-Use Plastic Waste Policy in 2018: what Will 2019 Hold in Store?, Law Research News Blog, 2019.

116 Q. Qiu, Z. Tan, J. Wang, J. Peng, M. Li and Z. Zhan, Extraction, enumeration and identification methods for monitoring microplastics in the environment, Estuarine, Coastal Shelf Sci., 2016, 176, 102-109.

117 M. Shen, D. Mao, H. Xie and C. Li, The social costs of marine litter along the East China Sea: Evidence from ten coastal scenic spots of Zhejiang Province, China, Sustainability, 2019, 11, 1807.

118 Shanghai Rendu Ocean NPO Development Center, Fishery and aquaculture marine debris survey report - in the Yellow Sea area of China, Yellow Sea Large Marine Ecosystem (YSLME) Phase II Project, Shanghai, China, 2019.

119 D. Eerkes-Medrano, R. C. Thompson and D. C. Aldridge, Microplastics in freshwater systems: A review of the emerging threats, identification of knowledge gaps and prioritisation of research needs, Water Res., 2015, 75, 6382.

$120 \mathrm{~W}$. Poortinga, L. Whitmarsh and C. Suffolk, The introduction of a single-use carrier bag charge in Wales: Attitude change and behavioural spillover effects, $J$. Environ. Psychol., 2013, 36, 240-247.

121 B. D. Hardesty and C. Wilcox, Understanding the Types, Sources, and At-Sea Distribution of Marine Debris in Australian Waters, CSIRO, 2011.

122 M. van der Mheen, C. Pattiaratchi and E. van Sebille, Role of Indian Ocean dynamics on accumulation of buoyant debris, J. Geophys. Res.: Oceans, 2019, 124, 2571-2590.

123 A. Pearce, G. Jackson and G. R. Cresswell, Marine debris pathways across the southern Indian Ocean, Deep Sea Res., Part II, 2018, 166, 34-42.

124 J. Reisser, J. Shaw, C. Wilcox, B. D. Hardesty, M. Proietti, M. Thums and C. Pattiaratchi, Marine plastic pollution in waters around Australia: Characteristics, concentrations, and pathways, PLoS One, 2013, 8, e80466.

125 M. Bai, L. Zhu, L. An, G. Peng and D. Li, Estimation and prediction of plastic waste annual input into the sea from China, Haiyang Xuebao, 2018, 37, 26-39.

126 C. Lin and S. Nakamura, Approaches to solving China's marine plastic pollution and $\mathrm{CO}_{2}$ emission problems, Econ. Syst. Res., 2019, 31, 143-157.

127 Z. Pan, H. Guo, H. Chen, S. Wang, X. Sun, Q. Zou, Y. Zhang, H. Lin, S. Cai and J. Huang, Microplastics in the Northwestern Pacific: Abundance, distribution, and characteristics, Sci. Total Environ., 2019, 650, 1913-1922.

128 C. N. Waters, J. Zalasiewicz, C. Summerhayes, A. D. Barnosky, C. Poirier, A. Gałuszka and A. P. Wolfe, The Anthropocene is functionally and stratigraphically distinct from the Holocene, Science, 2016, 351, aad2622.

129 W. R. Turrell, A simple model of wind-blown tidal strandlines: How marine litter is deposited on a midlatitude, macro-tidal shelf sea beach, Mar. Pollut. Bull., 2018, 137, 315-330.

130 F. M. Windsor, I. Durance, A. A. Horton, R. C. Thompson, C. R. Tyler and S. J. Ormerod, A catchment-scale 
perspective of plastic pollution, Glob. Change Biol., 2019, 25, 1207-1221.

131 S. D. Ling, M. Sinclair, C. J. Levi, S. E. Reeves and G. J. Edgar, Ubiquity of microplastics in coastal seafloor sediments, Mar. Pollut. Bull., 2017, 121, 104-110.

132 J. Teng, Q. Wang, W. Ran, D. Wu, Y. Liu, S. Sun, H. Liu, R. Cao and J. Zhao, Microplastic in cultured oysters from different coastal areas of China, Sci. Total Environ., 2019, 653, 1282-1292.

133 Z. Ge, H. Shi, X. Mei, Z. Dai and D. Li, Semi-automatic recognition of marine debris on beaches, Sci. Rep., 2016, 6, 25759.

134 J. F. Provencher, A. L. Bond, S. Avery-Gomm, S. B. Borrelle, E. L. Bravo Rebolledo, S. Hammer, S. Kühn, J. L. Lavers, M. L. Mallory, A. Trevail and J. A. van Franeker, Quantifying ingested debris in marine megafauna: a review and recommendations for standardisation, Anal. Methods, 2017, 9, 1454-1469.

135 F. Collard, B. Gilbert, G. Eppe, L. Roos, P. Compère, K. Das and E. Parmentie, Morphology of the filtration apparatus of three planktivorous fishes and relation with ingested anthropogenic particles, Mar. Pollut. Bull., 2017, 116, 182191.

136 J. Ding, J. Li, C. Sun, C. He, F. Jiang, F. Gao and L. Zheng, Separation and identification of microplastics in digestive system of bivalves, Chin. J. Anal. Chem., 2018, 46, 690-697.

137 T. Crutchett, H. Paterson, B. M. Ford and P. Speldewinde, Plastic ingestion in sardines (Sardinops sagax) From Frenchman Bay, Western Australia, highlights a problem in a ubiquitous fish, Front. Mar. Sci., 2020, 7, 526.

138 GESAMP, Guidelines for the Monitoring and Assessment of Plastic Litter in the Ocean, United Nations Environment Programme (UNEP) Printed, 2019.

139 FAO, The State of World Fisheries and Aquaculture 2018 Meeting the Sustainable Development Goals, Rome, Licence: CC BY-NC-SA 3.0 IGO, 2018.

140 R. Gunn, B. D. Hardesty and J. Butler, Tackling 'ghost nets': Local solutions to a global issue in northern Australia, Ecol. Manag. Restor., 2010, 11, 88-98.

141 R. R. McIntosh, R. Kirkwood, D. R. Sutherland and P. Dann, Drivers and annual estimates of marine wildlife entanglement rates: A long-term case study with Australian fur seals, Mar. Pollut. Bull., 2015, 101, 716-725.

142 Environment and Communications References Committee, Toxic Tide: the Threat of Marine Plastic Pollution in Australia, Commonwealth of Australia, Canberra, 2016.

143 J. C. Prata, J. P. da Costa, I. Lopes, A. C. Duarte and T. Rocha-Santos, Environmental exposure to microplastics: An overview on possible human health effects, Sci. Total Environ., 2020, 702, 134455.

144 Z. Cheng, H. Li, L. Yu, Z. Yang, X. Xu, H. Wang and M. H. Wong, Phthalate esters distribution in coastal mariculture of Hong Kong, China, Environ. Sci. Pollut. Res. Int., 2018, 25, 17321-17329.

145 L. C. M. Lebreton, S. D. Greer and J. C. Borrero, Numerical modelling of floating debris in the world's oceans, Mar. Pollut. Bull., 2012, 64, 653-661.

146 M. Kosmala, A. Wiggins, A. Swanson and B. Simmons, Assessing data quality in citizen science, Front. Ecol. Environ., 2016, 14, 551-560.

147 K. Syberg, A. Palmqvist, F. R. Khan, J. Strand, J. Vollertsen, L. P. W. Clausen, L. Feld, N. B. Hartmann, N. Oturai, S. Møller, T. G. Nielsen, Y. Shashoua and S. F. Hansen, A nationwide assessment of plastic pollution in the Danish realm using citizen science, Sci. Rep., 2020, 10, 17773.

148 J. H. Brand and K. L. Spencer, Potential contamination of the coastal zone by eroding historic landfills, Mar. Pollut. Bull., 2019, 146, 282-291.

149 K. Waldschläger, S. Lechthaler, G. Stauch and H. Schüttrumpf, The way of microplastic through the environment - Application of the source-pathway-receptor model (review), Sci. Total Environ., 2020, 713, 136584.

150 A. Ockelford, A. Cundy and J. E. Ebdon, Storm response of fluvial sedimentary microplastics, Sci. Rep., 2020, 10, 1865.

151 ASTM D8332-20, Standard Practice for Collection of Water Samples with High, Medium, or Low Suspended Solids for Identification and Quantification of Microplastic Particles and Fibers, ASTM International, West Conshohocken, PA, 2020, www.astm.org. 